\title{
Study on customer satisfaction of electric vehicle product quality characteristic
}

\author{
Jun $\mathrm{Ma}^{1, \text { a }}$, Tianjiao $\mathrm{Li}^{2, \mathrm{~b}}$, Zaiyan Gong ${ }^{3, \mathrm{c}}$ \\ ${ }^{1}$ Cao'an Road 4800, Jiading District, Shanghai, China \\ ${ }^{2}$ Cao'an Road 4800, Jiading District, Shanghai, China \\ ${ }^{3}$ Cao'an Road 4800, Jiading District, Shanghai, China \\ a majun.tongji@foxmail.com, bjolie_Itj@126.com, cgongzaiyan@foxmail.com
}

Keywords: electric vehicle, product quality characteristics, customer satisfaction, product life cycle Abstract. In recent years, driven by national policies, new energy automotive market in China was growing explosively, in which battery electric vehicles becomes the main force because of their low emission and high energy efficiency. Customer satisfaction research of product quality characteristic research for electric vehicle is different from the traditional vehicle. This paper analyzes the structure of battery electric vehicles, chooses AHP to construct the index system of battery electric vehicle product quality characteristics according to their definition and classification, standardize product characteristic positioning process and subsequently promise the reliability of product characterization and verification, which can assist auto companies to improve products directly in the design and production processes, optimize the product life cycle.

\section{Introduction}

In the twenty-first century, the traditional vehicle's high energy consumption and exhaust emissions issues have been widely concerned around the world. New energy vehicles with its low energy consumption, less emissions and other advantages, have caused more and more attention. In China, it should be the promotion of battery electric vehicles as the focus of the development, which is not only to achieve our country in the automotive industry technology "corner overtaking" leap-forward development of strategic choice, but also to ensure that China's auto industry in the future domestic and international markets Other international enterprises to compete for the necessary means and development path. ${ }^{[1]}$ At present, the national level to guide more focus on helping consumers to afford battery electric vehicles, but to be comfortable, whether to meet the daily needs of consumers, but also rely on customer satisfaction. The product quality satisfaction of the car provides the government, industry and business with a consumer perspective to systematically observe the quality of goods and services. Although satisfaction is usually described quantitatively, the true value of product quality satisfaction assessment is not the measurement data itself, but whether it can correctly use its satisfaction evaluation results. ${ }^{[2]}$

In the global automotive product satisfaction survey, more mature should be the first to push J.D. POWER, it is a market information services company, headquartered in the United States of California. J.D. POWER is principally engaged in the research, analysis, forecasting and customer satisfaction survey of the market. The company evaluates the quality or satisfaction by obtaining information from customer feedback. Its findings are also in the world with a certain authority. J.D. POWER's evaluation methods include new car quality research (IQS), automotive performance, operation and design research (APEAL) and durability quality assessment (VDS) and other parts. Among them, the new car quality research (IQS) and performance operation and design research (APEAL) are two different angles for car quality satisfaction survey. ${ }^{[3][4]}$

J.D. POWER on the evaluation of automotive product quality is more comprehensive, largely reflects the surveyed models of customer satisfaction, our research has some guiding significance. However, JDPOWER also has some shortcomings, such as: for the quality of the car research JDPOWER only count the number of problems did not involve the weight of the problem; the use of Asia-Pacific Standardized Questionnaire does not meet China's national conditions; less sample; Unreasonable; poorly investigative staff; lack of relevance to the report. ${ }^{[5]}$ 
At present, due to the actual customer purchase and retention limit, domestic and foreign battery electric vehicles in this area of product quality characteristics of the results of less research results, and most of the existing research is limited to the traditional fuel vehicle product satisfaction is simple Of the transplant to the battery electric vehicle to replace, evaluation, cannot really understand and solve the customer's battery electric vehicle essential needs, and therefore cannot meet the real needs of customers. ${ }^{[6][7]}$

This paper will be based on the satisfaction evaluation system of the traditional vehicle product quality characteristics. Battery electric vehicles and traditional cars in the technical aspects of the similarities and differences were analyze. And then get battery electric vehicle unique throughout the life cycle process for customer satisfaction indicators of quality characteristics, through the research with 3,414 samples covered the 21 major cities in China, establish a battery electric vehicle satisfaction evaluation system from the perspective of product quality characteristics. With a combination of theory and practice, further study of the key factors that consumers consider when they buy the battery electric vehicles.

\section{Theoretical basis}

Definition and structure of battery electric vehicles. The definition of new energy vehicles refers to the vehicles with unconventional fuels such as oil and natural gas as a driving force or conventional fuels, but in the drive power plant, such as power output control and vehicle driving with a new type or new technology, and ultimately formed in the technical principle with a certain advanced, in practical application with new technology, mechanical structure with a new structure. New energy vehicles typically include hybrid electric vehicles (PHEV, HEV), battery electric vehicles (BEV), fuel cell electric vehicles (FCEV), and other vehicles with unconventional energy sources as fuel-driven products ${ }^{[8][9]}$.

Battery electric vehicles are the vehicles with car power providing all or part of the power (rechargeable energy storage batteries, such as lead-acid batteries, lithium-ion batteries, etc.) under the existing traffic roads, safety collisions and other national laws and regulations. It can directly use the external power supply for the battery charge and through the battery power into mechanical energy to drive. Battery electric vehicles, in comparison with the traditional car, have many advantages: 1 , in the discharge, can achieve zero or near zero emissions; 2 , to reduce the traditional car in a variety of tubing such as oil, brake oil and other oil emissions handling brought about by environmental pollution; 3, high energy conversion efficiency can improve the energy use of the economy; 4, to improve the driving drive efficiency; 5 , in driving to achieve smooth ride, accelerate linear, low noise. ${ }^{[10]}$

The battery electric vehicle components currently include: battery, motor and related electronic control system, the three components, which is currently the biggest difference with the traditional engine car, and other basic equipment is similar with traditional engine car. Initially, battery electric vehicles are traditional internal combustion engines and fuel tanks into motor drive and power battery pack, but this structure is more complex, and is not conducive to the performance of the motor, resulting in low efficiency. ${ }^{[11]}$ At present, battery electric vehicles mainly composed of the existing traditional car similar structure, which can load the relevant drive system chassis (some are same with traditional car, and some are newly developed), motor and battery pack and its controller. ${ }^{[12]}$ Compared with the traditional car, the energy source, the transmission mode, the layout of the motor and its variable speed device are the most obvious difference. Based on the characteristics of the drive motor, the current battery electric vehicle is divided into four types: conventional type, no transmission type, no differential type and electric wheel-type. It offers a variety of options for structural design.

Product quality satisfaction. With the increasingly fierce competition in globalization, enterprises generally face with the problem of increasing product complexity, shortening product life cycle and improving proportion of personalized products. Europe and the United States in the product development process, has accumulated a wealth of experience, and gradually summed up and established such as product quality planning (APQP), potential failure mode and consequences 
analysis (FMEA), production approval process (PPAP), product maturity management. Product life cycle management and collaborative product development and other methods and tools to effectively enhance the quality of its design.

Dr. Zhu Lan's "Handan Quality Manual" has been specifically designed for "design quality" and has clearly stated that the design quality includes: quality of design; quality of market research; conceptual quality Quality of concept and quality of specifications. (CMI), which is based on the software process capability, and later put forward the project management according to the different requirements and standards from the point of view of project management. The software development model (CMM) based on software process capability has been proposed by the United States Carnegie Mellon University Software Engineering Research Institute (SEI) Maturity model (PM3). The three major US tool companies (GM, Chrysler, Ford) released the five tool manual from the quality point of view to participate in product design and development and production of the whole process. $^{[13]}$

Automobile quality evaluation with the use of new technologies and the number of new car development and the continuous development and accumulation, and gradually be improved. ${ }^{[14]}$ After the establishment of the process, evaluation of automotive product quality usually through the checklist or positive, negative list of the failure to be implemented, and the need to continue to add and update in practice. ${ }^{[15][16]}$

In the measurement of product quality satisfaction performance, usually need to use the product characteristics to products in each attribute areas reflected in the nature of the product in the course of the operation of the role of different status and different weight is also different. ${ }^{[17][18]}$ And the product presented in front of the consumer is the result of the interaction of different attributes. The characterization of the primary and secondary characteristics indicates that the product is expected to be in the minds of the consumer, reflecting the subjective aspects of the level of performance. With the study of product characteristics, expert interviews and analytic hierarchy process can be used to obtain product characteristics of the primary and secondary indicators. ${ }^{[19]}$

\section{Methods}

AHP method. In recent decades, after decision-making science has undergone continuous exploration and research practice based on the system engineering, a perfect theory and system and the corresponding application method have been gradually formed. In the process of decision-making science development, people are aware that complex mathematical models will make the original complex decision-making becomes more difficult, the field of operations in the individual selection and judgment of the important landmark node, to re-study the decision-making process Human The characteristics of thinking. ${ }^{[20]}[21]$

The use of AHP is divided into four basic processes. First, we need to establish a hierarchical model suitable for practical analysis. Secondly, we make a comparison between each factor at each level to construct a comparative judgment matrix. Then we need to calculate the single order weight vector. The calculation of the consistency test is carried out to determine the credibility of the calculation result. Finally, the total sorting weight vector is calculated and the consistency test is performed to determine the credibility of the calculation result. This process is in accordance with the order from the top to the bottom of the order, the level of single-order results that is the result of the overall sort. ${ }^{[22][23]}$

Establish a hierarchical model. The main key process of AHP method in the analysis of the decision-making process is: First, to clarify the problem of rationality, to decompose the problem level, so as to construct a hierarchical analysis of the structural model, and the decision-making problem is divided into a single element composed of modules. Second, in accordance with the principle of no-association between each other, a single element by grouping attributes and to ensure that the elements between the upper and lower levels can form all or part of the dominant role in the top-down level between the formation of dominant relations, this relationship is hierarchical relationship. The bottom layer is usually referred to as the program layer, or also called the action layer, mainly a specific single decision-making program; the main purpose is to achieve the set goals 
or results can be formulated to implement the implementation of measures or the need for path selection programs specific behavior. ${ }^{[24]}[25]$

Construct a comparative judgment matrix. First, it's the hierarchical structure of the construction and finalization. The core work is to develop the elements of the upper and lower elements of the relationship between membership and dominance. Then the determination of the weight value of the single element in each level is usually faced with the difficulty that the weight value is not easy when determining, especially when determining the specific weight ratio of the factor influencing the factor in the factor. For the more complex problems, the weight of the elements often cannot be directly and easily obtained, then it is necessary through the decision-makers to determine the experience of judging matrix to give a way to derive their weight. In the sub-criterion layer, it is necessary to establish a pairwise comparison matrix of various factors, in which the judgment value of the judgment matrix usually reflects the mutual understanding of the mutual importance. ${ }^{[26]}$

Calculate the single order weight vector and do the consistency check. The maximum eigenvalue $\lambda \max$ and its corresponding eigenvector $\mathrm{W}$ are calculated for each pair of comparison matrices. Consistency index and random consistency ratio are used to verify the consistency. In the case of a binary comparison matrix constructed between elements, assignments are usually taken by expert scoring, or by means of the actual experience of the evaluator. The effective comparison judgment matrix should be passed to the decision maker after the consistency test, and the matrix must be properly corrected when the consistency test cannot be passed. The inspection procedure is as follows:

1) Calculate the largest eigenvalue of the pair of comparison matrices, usually use $\lambda_{\max }$ to represent

$$
\begin{gathered}
R_{i}=\left(r_{i 1}, r_{i 2}, \ldots, r_{i n}\right) \\
\lambda_{\max }=\sum_{i=1}^{n} \frac{(A w)_{i}}{n w_{i}}
\end{gathered}
$$

2) Calculate consistency indicators, usually expressed as CI:

$$
C I=\frac{\lambda_{\max }-n}{n-1}
$$

Calculate the random consistency ratio, usually expressed as CR:

$$
C R=\frac{C I}{R I}
$$

RI (Random Index) is the average random consistency index, which is related to the order of the judgment matrix. When the CR value must be less than 0.1 , the result of the single sort of order has a convincing consistency, otherwise the element value of the judgment matrix should be adjusted. ${ }^{\text {[27] }}$

Calculate the total ranking weight vector and do the consistency test The above result is a weight vector for a group of elements in the corresponding upper part of the corresponding element. When the final decision maker makes a decision on all the elements, it is necessary to consider the total element of the uppermost element from the lowest level. The weight vector is calculated so that the final plan can be drawn and chosen by the decision maker. And this requires the adoption of a single level of the weight of the elements from top to bottom to synthesize, resulting in the lowest and the highest relative weight of the synthesis. ${ }^{[28]}$

\section{Results}

In the construction of automobile product quality objective performance evaluation index system, we should follow the comprehensive, representative, distinguishable, economic, operability and relative stability of the six basic principles. Product quality objective performance evaluation index system to be able to comprehensively evaluate the objective of the performance of automotive products. However, there are many factors that affect the objective performance of product quality. It is 
impossible to include all the factors in the system. Therefore, it is necessary to select the most representative factor in this aspect as the evaluation index. At the same time, the indicators can not be replaced by each other, if an indicator and other indicators difficult to distinguish between the lack of independence, then it can not be used as an evaluation index. Although the indicators need to consider the economy, although a certain indicator is very useful, but in order to obtain the data of this indicator need to consume a lot of manpower and resources, greater than the benefits can be obtained, the index should be discarded. Manipulation is the feasibility of indicators and related data, it is to establish a customer satisfaction evaluation system must be considered a very important principle, from this, and then a comprehensive system can not be applied. ${ }^{[2]}$ After the establishment of the customer satisfaction evaluation index system, it is necessary to maintain the relative stability of the basic indicators, which will be conducive to the further development and improvement of the evaluation system. ${ }^{[30][31]}$

Select evaluation indexes of battery electric vehicle product quality satisfaction. In this paper, battery electric vehicle customer satisfaction index mainly comes from the traditional car new car quality research, performance, operation and design research and comparison of the characteristics of battery electric vehicles, drawing lessons from the 2015 "China's new energy automotive industry development report". According to the characteristics of battery electric vehicle product quality satisfaction and the construction of evaluation index system of customer satisfaction, combined with the previous research results and the actual situation, this paper selects the following seven aspects to evaluate whether the quality of products meet consumer expectations:

(1) Comfort performance: the quality of the comfort of the car quality determined by many factors, including driving, acoustics, space, ventilation, storage space, driver assistance systems, etc., which reflect the overall comfort of this product car Performance quality, thus affecting consumer satisfaction.

(2) Driving performance: refers to the overall shape of the car design, car color and paint the quality of the car's space layout is reasonable, the car decoration and configuration is innovative. The shape of the car product is also an important factor in influencing the consumer's purchase of the car and satisfaction after the purchase. The car company needs real-time understanding of the needs of the consumer to better meet the consumer.

(3) Design: the design here does not mean that the design of the aesthetic level, but the need for consumers to evaluate the appearance and interior parts and elements of the quality of the pros and cons. For example: whether the door (including the front door, back door, luggage compartment door) is not easy to open / close, whether the body paint peeling off, the interior material is easy to stain / wear and so on. ${ }^{[32]}$

(4) Energy consumption: This is different from the traditional fuel car one of the main evaluation content, mainly to consider driving range and power consumption in two parts, because battery electric vehicles use the battery as a source of energy, so the use of battery state continued Driving mileage has become the most critical indicator of the performance of battery electric vehicles. Once the battery runs out, you must charge the battery electric vehicle, but the charging time is relatively long compared to the traditional car fuel is much longer, so a single charge driving range of the most of battery electric vehicle core indicators, but also consumers in the choice of battery electric vehicles are most concerned about the performance. For example: whether the mileage is full of electricity than the manufacturers described the mileage is too short, when the weather is still a significant decline in battery life, air conditioning, power consumption is too large and so on.

(5) Safety performance: battery electric vehicle safety performance evaluation, in addition to analogy to traditional fuel vehicles, field of vision lighting, active safety and passive safety of three aspects, the need for battery electric vehicle energy specificity and consider the battery safety.

(6) Charging convenience: charging convenience is battery electric vehicle consumers in terms of product quality care about, including the quality of charging pile, the quality of charging interface, fast charge and slow charge time and the manufacturer is time difference More and so on.

(7) Information exchange: Information exchange of battery electric vehicles. In addition to analogical entertainment, navigation and communication systems similar to traditional fuel vehicles, 
the quality assessment of vehicle information display systems is quite different. For example, when charging / current / Voltage display is normal and so on.

Assess the importance of indexes. In order to determine the relative weight of each index factor, this paper designed the objective indicator of the objective performance index of battery electric vehicle product quality. The experts in the industry, consultants and internal experts of the automobile company as the survey object, in May 2016 in the form of a line to issue, issued a total of 30 questionnaires, the recovery of valid questionnaires are 26 copies. Scoring is divided into five dimensions, and the importance is divided into very important, important, general, not important, very important, corresponding to the scores were $[5,4,3,2,1] .{ }^{[33]}$ Battery electric vehicle product quality evaluation of the objective performance of the test indicators, is to remove those who have little impact on the evaluation results indicators. In this case, it is assumed that there are $m$ indicators in a certain level of the evaluation index system, and the experts are invited to comment. After the expert reviews are finished, the opinions of the experts are analyzed, mainly in the following aspects:

(1) Concentration:

$$
\widetilde{E}_{j}=\frac{1}{k} \sum_{i=1}^{k} E_{j} n_{i j}
$$

Where $\widetilde{E}_{j}$ denotes the magnitude of the evaluation of the $i$-th indicator; $E_{j}$ denotes the magnitude of the $\mathrm{i}$-index to the $\mathrm{j}$-th level; $\mathbf{n}_{\mathrm{ij}}$ denotes the number of experts who evaluate the $\mathrm{i}$-th index as $\mathrm{j}$-level.

(2) Degree of dispersion:

$$
\delta_{j}=\sqrt{\frac{1}{k-1} \sum_{j=1}^{5} n_{i j}\left(E_{j}-\tilde{E}_{j}\right)}
$$

$\delta_{\mathrm{j}}$ denotes that for the $\mathrm{i}$-th index, the degree of discretization of the expert's evaluation is opposite to that of the above-mentioned concentration level. If the expert evaluation is concentrated, then $\delta_{\mathrm{j}}$ is relatively small, otherwise $\delta_{\mathrm{j}}$ is larger.

(3) degree of coordination:

$$
V_{j}=\frac{\delta_{j}}{\tilde{E}_{j}}
$$

Among them, $\widetilde{\mathrm{E}}_{\mathrm{j}}$ is the evaluation of experts on the index, the greater the value, the indicators become more important. $\delta_{\mathrm{j}}$ is the concentration of expert evaluation of the degree of concentration, the smaller the value, the more concentrated the views of experts. $\widetilde{\mathrm{E}}_{\mathrm{j}}$ and $\delta_{\mathrm{j}}$ are the absolute indexes, the two values that sometimes not exactly the same, then you need to use $V_{j}$ to judge, the smaller $V_{j}$ that the more important indicator of this indicator. ${ }^{[34]}$

Establish a hierarchical model. Based on the understanding of the traditional automobile new car quality satisfaction evaluation index system and the analysis of the battery electric vehicle product quality objective evaluation system after the establishment of the principles and indicators of the characteristics of the traditional car new car quality satisfaction evaluation index system based on the addition of battery electric vehicle product quality satisfaction important impact indicators, can be roughly battery electric vehicle product quality objective evaluation index system. After the integration, screening, classification, verification, this article will be divided into four levels of this system, each level is extended from the previous level of indicators, the next level of evaluation is the next level of the integrated evaluation of the indicators result.

In the following study, the objective performance of battery electric vehicle product quality is divided into seven first-level indexes: comfort performance, driving performance, design, energy consumption, safety performance, charging convenience and information exchange. The seven indicators will be further divided into 27 secondary indicators. And in the construction of hierarchical 
structure, as far as possible so that each level of the factors is independent of each other, so that the next step can be simplified, as a layer of refined battery electric vehicle product quality objective evaluation indicators. Specific indicators are shown in Table 1.

Table 1 battery electric vehicle product quality satisfaction index levels

\begin{tabular}{|c|c|c|}
\hline Target layer & First-level indexes & Secondary indexes \\
\hline \multirow{27}{*}{ 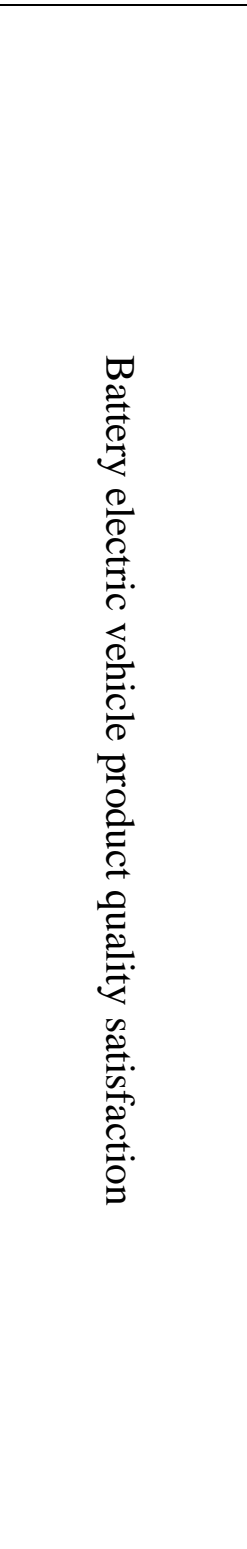 } & \multirow{6}{*}{$\begin{array}{c}\text { Comfort } \\
\text { performance }\end{array}$} & Driving comfort \\
\hline & & Acoustic comfort \\
\hline & & Space comfort \\
\hline & & Ventilation comfort \\
\hline & & Storage space \\
\hline & & Driver Assistance System \\
\hline & \multirow{6}{*}{$\begin{array}{c}\text { Driving } \\
\text { performance }\end{array}$} & Steering performance \\
\hline & & Straight running performance \\
\hline & & Curve running performance \\
\hline & & Braking performance \\
\hline & & Accelerated performance \\
\hline & & Start performance \\
\hline & \multirow{2}{*}{$\begin{array}{c}\text { Energy } \\
\text { consumption }\end{array}$} & driven distance \\
\hline & & power consumption \\
\hline & \multirow{2}{*}{ Design } & Exterior \\
\hline & & Interior \\
\hline & \multirow{5}{*}{$\begin{array}{c}\text { Safety } \\
\text { performance }\end{array}$} & Vision and lighting \\
\hline & & Active safety \\
\hline & & Passive safety \\
\hline & & Battery safety \\
\hline & & Anti-theft \\
\hline & \multirow{2}{*}{$\begin{array}{l}\text { Charging } \\
\text { convenience }\end{array}$} & Charging time consuming \\
\hline & & Charging interface \\
\hline & \multirow{4}{*}{$\begin{array}{l}\text { Information } \\
\text { exchange }\end{array}$} & Audio-visual entertainment \\
\hline & & Navigation System \\
\hline & & Communication Systems \\
\hline & & Vehicle information display system \\
\hline
\end{tabular}

Determine the weights of the composite indexes. The ultimate goal of this paper is to calculate the weight of the index layer to the target layer, so as to determine the impact of each index in the target layer on the objective evaluation of battery electric vehicle product quality, for the next step to investigate the data and automotive product quality objective calculation of the final calculation and analysis. In order to achieve this goal, we need to top-down the single-level weight to calculate the synthesis, in order to obtain the program layer relative to the target layer of the comprehensive weight. According to the above single-level index weight calculation, we get the final total weight of the index, that is, the index weight of customer satisfaction. ${ }^{[34]}$

Yaahp software is often used for AHP decision-making, it can help researchers to build a regular or unconventional level map, and to facilitate the user in a standard layer to join the judgment matrix, hierarchical chart used to organize all the relevant criteria to logic. Of course, in the definition of specific issues and in the hierarchy map to enter the relevant indicators, the data information of the process has a user to complete. Yaahp software can be in the mathematical calculation of the process 
of rigorous quantitative calculation and qualitative proof of the level of priority and related factors to determine the combination of decision-making, which can be simplified to simplify the series of factors compared to select the output of the process of integration results, to help decision makers to make the best qualitative decision under the same time, but also to provide a clearer decision-making idea. ${ }^{[35]}$

The weight of the indicators under a certain index is also referred to as the weight vector of the single criterion. To obtain the weight of the index object under the final target layer, we need to use the weight of the single criterion. The results are shown in Table 2.

Table 2 The weights of the composite indexes

\begin{tabular}{|c|c|c|}
\hline Target layer & First-level indexes & Secondary indexes \\
\hline \multirow{27}{*}{$\begin{array}{ll}\mathscr{W} \\
ٍ\end{array}$} & \multirow{6}{*}{$\begin{array}{c}\text { Comfort performance } \\
0.158\end{array}$} & Driving comfort 0.025 \\
\hline & & Acoustic comfort 0.033 \\
\hline & & Space comfort 0.033 \\
\hline & & Ventilation comfort 0.028 \\
\hline & & Storage space 0.016 \\
\hline & & Driver Assistance System 0.022 \\
\hline & \multirow{6}{*}{$\begin{array}{c}\text { Driving performance } \\
0.126\end{array}$} & Steering performance \\
\hline & & Straight running performance 0.020 \\
\hline & & Curve running performance 0.016 \\
\hline & & Braking performance 0.015 \\
\hline & & Accelerated performance 0.031 \\
\hline & & Start performance 0.023 \\
\hline & \multirow{2}{*}{$\begin{array}{c}\text { Energy consumption } \\
0.115\end{array}$} & driven distance 0.022 \\
\hline & & power consumption 0.062 \\
\hline & \multirow{2}{*}{$\begin{array}{l}\text { Design } \\
0.226\end{array}$} & Exterior 0.114 \\
\hline & & Interior 0.112 \\
\hline & \multirow{5}{*}{$\begin{array}{c}\text { Safety performance } \\
0.143\end{array}$} & Vision and lighting 0.031 \\
\hline & & Active safety 0.030 \\
\hline & & Passive safety 0.033 \\
\hline & & Battery safety 0.022 \\
\hline & & Anti-theft 0.027 \\
\hline & \multirow{2}{*}{$\begin{array}{c}\text { Charging convenience } \\
0.136\end{array}$} & Charging time consuming 0.052 \\
\hline & & Charging interface 0.084 \\
\hline & \multirow{4}{*}{$\begin{array}{c}\text { Information exchange } \\
0.096\end{array}$} & Audio-visual entertainment 0.023 \\
\hline & & Navigation System 0.035 \\
\hline & & Communication Systems 0.012 \\
\hline & & Vehicle information display system 0.027 \\
\hline
\end{tabular}

With the weight of the indicators, it can be calculated by the weight of the brand battery electric vehicle models of product quality satisfaction. The formula is as follows:

$$
E V-I Q S=\sum_{i=1}^{k} W_{i} S_{i}
$$

EV-IQS which represents the product quality satisfaction of a battery electric vehicle models, $S_{\mathrm{i}}$ is the model score of a consumer for a certain indicator, $\mathrm{W}_{\mathrm{i}}$ is the comprehensive weight of the index.

\section{Conclusions}

Evaluation results of battery electric vehicle product quality satisfaction. After determining the weight of each index, the satisfaction data of 3413 consumers in 21 cities will be calculated and analyzed, and the consumers' quality evaluation of battery electric vehicle product satisfaction can be obtained. 
The survey covers low-end, mid low-end, high-end and luxury car, four market segments. Involving a total of 18 brands, 29 models. Different levels of consumer expectations of product quality and evaluation criteria are also different. Luxury car's product quality objective performance is better than other levels, but the performance of luxury cars mainly due to the appearance of interior, comfort and other aspects, and EV attributes are highly related to the convenience of charging, energy consumption, information exchange is not an obvious advantage. In addition, the low-end car is better than the mid-range car, which is mainly due to lower expectations of low-end car owners. Specific results shown in Fig. 1 and Fig. 2

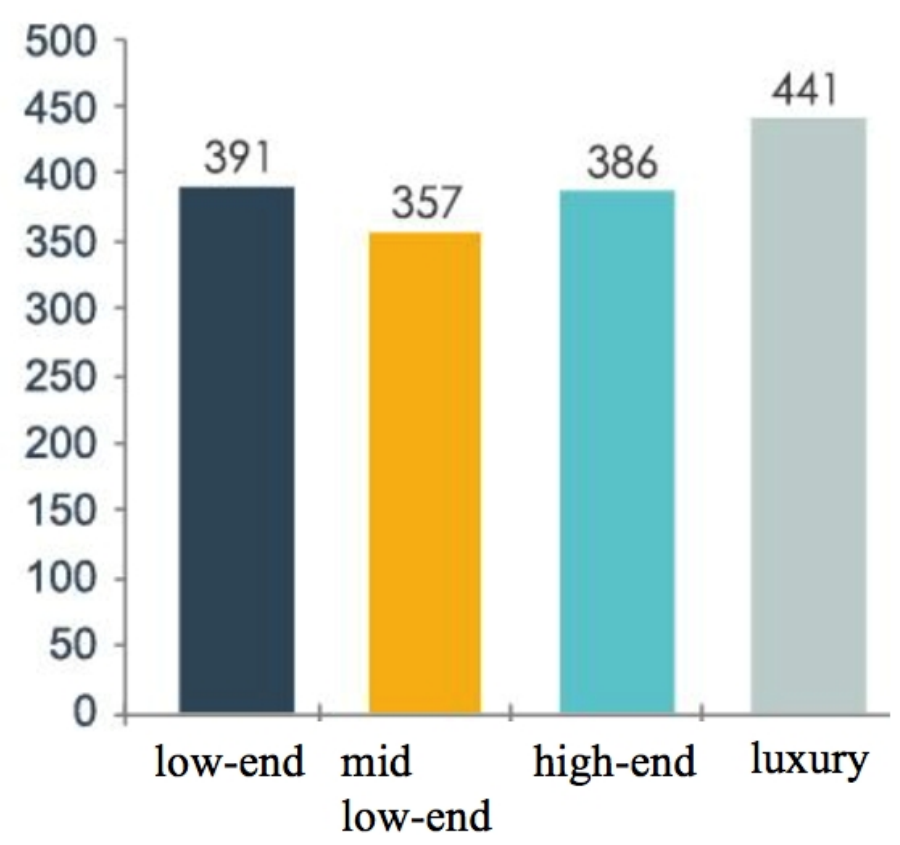

Fig. 1 Different levels of consumers' quality satisfaction evaluation

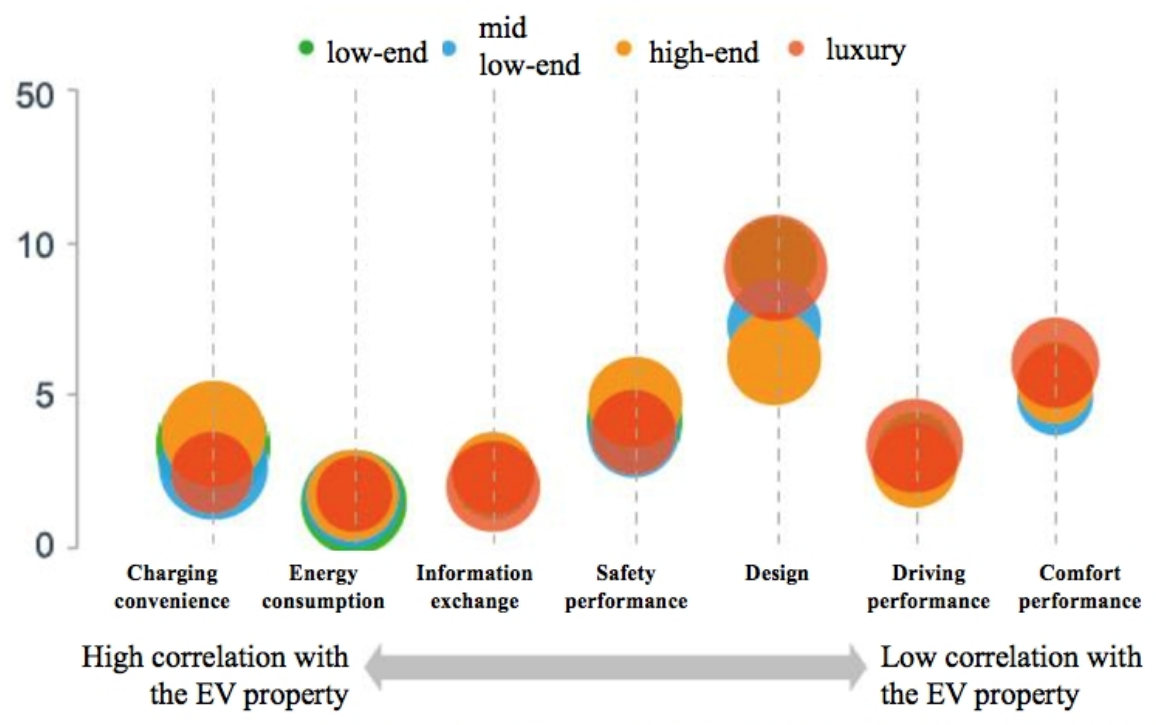

Note: The bubble area represents the weight of each level indicator

Fig. 2 The weight of indicators for different levels

In addition, in the survey, it can be divided into different levels of consumers of battery electric vehicle product evaluation of the objective performance of the list of the following Fig. 3. 

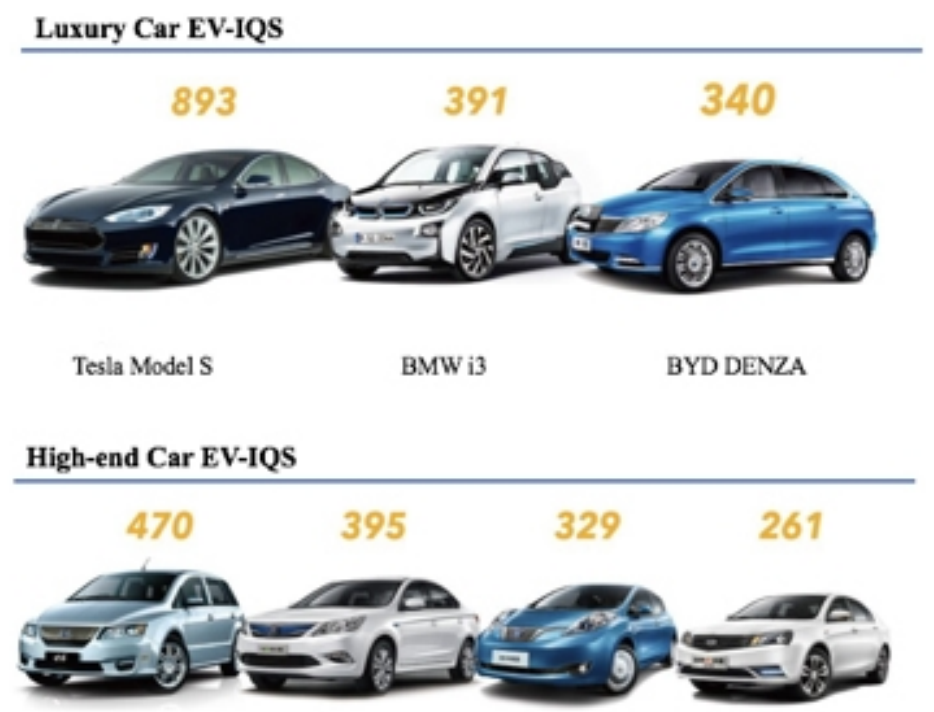

BYD e6 Changan EADO Venucia e30 EMGRAND EV

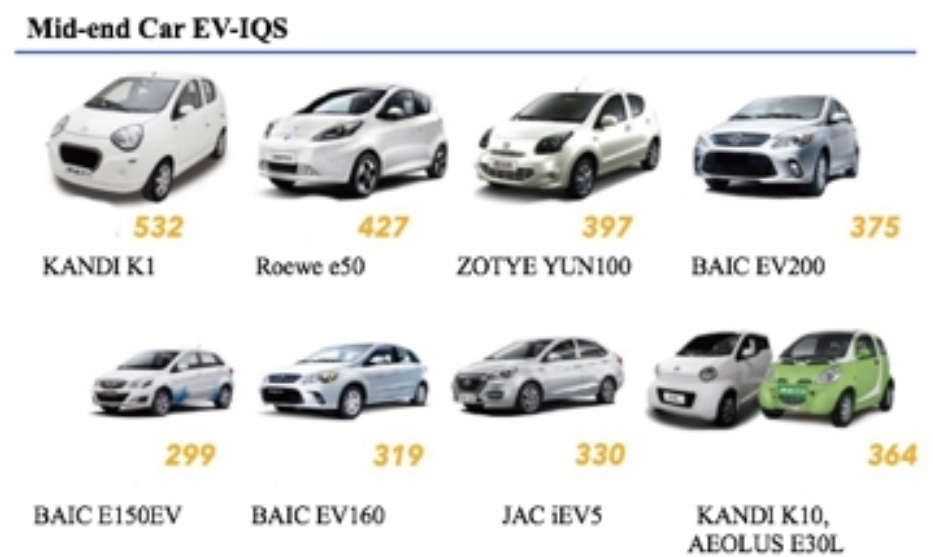

Low-end Car EV-IQS

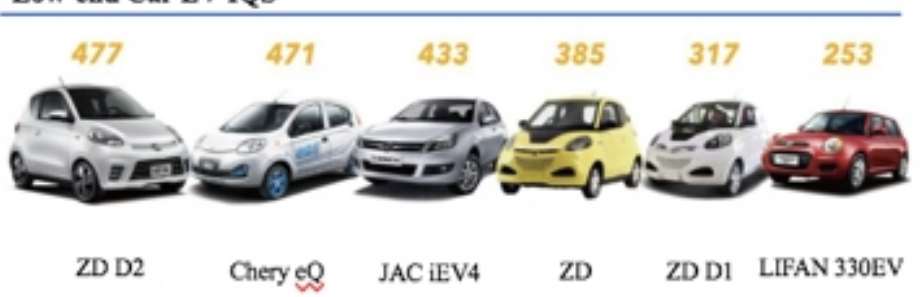

Fig. 3 The EV-IQS for NEVs of different levels

\section{Summary}

In this paper, the study object is customer satisfaction of battery electric vehicle product quality characteristics. First, battery electric vehicle structural characteristics and performance (the main analysis is different from the traditional car characteristics) is analyzed, while access to information on product quality satisfaction theory. This paper puts forward the necessity of product quality satisfaction evaluation of battery electric vehicle. On the basis of traditional automobile customer satisfaction evaluation system, the customer satisfactions of battery electric vehicle and traditional automobile are compared, and the quality satisfaction index system of battery electric vehicle is formed, which reflecting that the indexes of design, driving performance, safety performance and charging convenience are more concerned about by the consumers in the purchase of battery electric vehicles. 
After establishing the evaluation index system and the hierarchical structure model of the battery electric vehicle, the weight of each index under the criterion is calculated by the analytic hierarchy process(AHP) with industry experts' scoring, and the consistency result is tested and the requirements are met. Finally, the weight of the single criterion is synthesized from top to bottom, and the weight and evaluation formula of battery electric vehicle customer satisfaction are formed. After determining the weight of each index, the results of satisfaction research of 3413 consumers in 21 cities are calculated and analyzed, and the consumers' product quality satisfaction evaluation of battery electric vehicles are obtained.

For the results of the study, it is necessary for the production enterprises to carry out the research and the satisfaction evaluation of battery electric vehicle products, improve directly in the design and production processes, optimize the product life cycle, and obtain a better market status.

\section{References}

[1] Mei'e Tian: The necessity and trends of electric vehicle. Journal of Xi'an Petroleum University (NATURAL SCIENCE EDITION), 2010, 25 (5): P89-91 (in Chinese)

[2] Ruibin Jiang: Development and challenge of electric vehicle. Mechanical Engineer, 2009 (2): P23-25 (in Chinese)

[3] J. D. Power Associates. 2009 China automotive performance, operation and design research. 2009,19

[4] Jingjing Sheng: Study on the quality inspection method of automobile design. Automotive Engineer, 2011,2: P19 (in Chinese)

[5] Alejandra M. Munoz: Sensory evaluation in quality control: an overview, New developments and future opportunities. Food Quality and Preference, 2002.13(6): P329-339

[6] Fengrong Zhang, Lili Wang: Quality management and control. Beijing: China Machine Press, 2006,25 (in Chinese)

[7] N. Kano, N. Seraku, F. Takahashi, S. Tsuji: Attractive and Must -be Quality, The Japanese Society for Quality Control,1984,14(2): P39-48

[8] Fengchang Zhao: Analysis on electric vehicle structure layout and design application. Tech-Research, 2015 (21): P 79-79 (in Chinese)

[9] Bo Zhao: Electric vehicle technology and its industrialization. Northeastern University, 2010 (in Chinese)

[10]Zhengyao Zou, Yaoping Wang: New energy vehicle technology. National Defense Industry Press, 2014, P120-125 (in Chinese)

[11]Lijun Zhao, Qinzhi Tong. The structure and principle of electric vehicle. Peking University press, 2012, P93-95 (in Chinese)

[12]Chongliang Xu, Chuanfa Zhang: Electric vehicle and hybrid power. Shandong University press, 2013, P8-10 (in Chinese)

[13]Joseph.M. Juran, Joseph.A.. Juran Defeiou: Quality Manual. Renmin University of China press, 2014,10

[14]Chuanmin Zhu, Ming Chen, et al. Research and application of product maturity management strategy in collaborative design. Manufacturing automation, 2010,9 (32): 14 (in Chinese)

[15]Hailin Wang, Yan Hou, Jinsheng Guo. Modern quality management. Beijing: economic management press, 2005,7 (in Chinese)

[16] Yadav O. P, Parveen S.G.: Customer satisfaction driven quality improvement target planning for 
product development in automotive industry. Interactional Journal of Production Economics,2008,113,P997-1000

[17]Crawford: New product management, Beijing: Renmin University of China press, 2006

[18]Mark Perry: Strategic marketing management, Beijing: China financial and Economic Publishing House, 2003

[19] Fei Li, Qian Liu: The market positioning strategy of comprehensive model. Nankai management review, 2004, 7 (5): P39-43 (in Chinese)

[20]Zhe Wu: Research on customer satisfaction evaluation of automobile industry based on AHP. Doctor. Tianjin University, 2012 (in Chinese)

[21] Hongcai Sun, Ping Tian, et al. Analytic hierarchy process (AHP) and decision science. National Defense Industry Press, 2011, 1-5 (in Chinese)

[22] Chunhua Pu: Research and application of analytic hierarchy process. Master. North China Electric Power University, 2008 (in Chinese)

[23]Lianfen Wang, Shubai Xu: The analytic hierarchy process. Renmin University of China press, 1990, 1-10 (in Chinese)

[24]Xiaoyan Zhan: Research and application of a combined algorithm model in software cost estimation. HeFei University of Technology, 2010 (in Chinese)

[25] Binglin Bei: Comprehensive evaluation of workshop layout. Shanghai Jiao Tong University, 2007 (in Chinese)

[26] Ying Lai: Research and implementation of Patent Classification Based on neural network. Hebei University of Technology, 2011 (in Chinese)

[27]Ran Wang: Research on purchasing management strategy based on material subdivision. Shanghai Jiao Tong University, 2012 (in Chinese)

[28]Lijia Zhang: Research on the identification of accounting fraud of listed companies by using analytic hierarchy process. Tianjin University of Finance Economics, 2010 (in Chinese)

[29]Xiaojie Lan, Lei Yao, Shuai Wu: Study on customer satisfaction index system of automobile, Automobile industry research, 2005 (9): P21-23

[30]Cizelj R.J, Mavko B,Kljenak: Component reliability assessment using quantitative and qualitative data. Reliability Engineering and System Safety,2001,71,81-95

[31]Peteraf M A: The Cornerstones of Competitive Advantage: A Resourcebased View. Strategy management Journal,1993,14:179

[32] Stephen K.Brown and Min Cheng. VOLATILE ORGANIC COMPOUNDS (VOCs) IN NEW CAR INTERIORS.15th International Clean Air\& Environment Conference.Nov26-30, 2000.Sydney, CASANZ: 464-468

[33] J. Takala, A. Bhufha, K. Phusavat. Proposed verification method for the content suitability of the customer satisfaction survey. Industrial Management \&amp; Data Systems,2006

[34]Huihui Wang: Research and case analysis of customer satisfaction measurement Doctoer. Wuhan University of Technology, 2004 (in Chinese)

[35] Yong Li. Research on customer satisfaction index model and its evaluation method. Doctor. China University of Mining and Technology (Beijing), 2008 (in Chinese) 